\title{
JURISDICCIÓN CONSTITUCIONAL: ECOS DEL ARGUMENTO CONTRAMAYORITARIO
}

\author{
CONSTITUTIONAL JURISDICTION: ECHOES \\ FROM THE COUNTERMAJORITARIAN DIFFICULTY
}

\section{Mauro Arturo RIVERA LEÓN}

RESUMEN: Este artículo pretende hacer ciertas clarificaciones en torno a los conceptos de legitimidad y su relación con la jurisdicción constitucional. Para ello, se utilizará el análisis del argumento contramayoritario, es decir, la objeción hecha a la jurisdicción constitucional —inicialmente a la Judicial Review por parte de Alexander Bickel- de su carente legitimidad en la anulación de decisiones tomadas por un cuerpo colegiado y teóricamente representativo de los intereses populares. Se intentará demostrar que esta objeción no es tan fuerte como se ha pretendido; al analizar diversas argumentaciones se emprenderá una defensa de la legitimidad de la jurisdicción constitucional como elemento positivo del Estado constitucional de derecho. En la sección final se realizarán algunas conclusiones y consideraciones del argumento contramayoritario basado en los diversos conceptos de contramayoría.

Palabras clave: Contramayoría, legitimidad, jurisdicción constitucional, Judicial Review, Marbury vs. Madison, argumento contramayoritario, Bickel.
ABSTRACT: This article pretends to make certain considerations to clarify the concepts of legitimacy and its relation to constitutional jurisdiction. For this, I will mainly analyze the countermajoritarian difficulty, which is the objection made to constitutional jurisdiction —and initially to Judicial Review by Bickel - of its lacking legitimacy for invalidating decisions from a collegiate body and theoretically representative of popular interest. I will pretend to demonstrate that this objection is not as strong as it has been argued and analyzing different argumentations I will provide a defense of constitutional jurisdiction as a positive element of a constitutional rule of law. In the final section some considerations and conclusions of the countermajoritarian difficulty will be drawn based on the different concepts of countermajority.

Descriptors: Countermajoritarian, Legitimacy, Constitutional Jurisdiction, Judicial Review, Marbury vs. Madison, Countermajoritarian Difficulty, Bickel. 
A Mara Rocio

\section{INTRODUCCIÓN*}

La idea de la fuerza normativa constitucional es particularmente fuerte y aceptada en la actualidad. La Constitución ha evolucionado de una forma sorprendente; ha pasado de ser una Constitución orgánica y toral en la regulación estatal, para situarse en el centro del debate político y abandonar su exclusiva organicidad para ser una Constitución dadora de derechos. Esto ha generado que la idea del Estado como rechstaat evolucione para conceptualizar al ideario Estado de derecho como un Estado constitucional ${ }^{1}$ y democrático de derecho. La aparente tautología del término es una evidente prueba del notable progreso constitucional en los últimos años.

El fenómeno nominado neoconstitucionalismo ${ }^{2}$ ha comenzado a permear en distintos órdenes jurídicos a partir del corolario de la supremacía constitucional. Este cambio fue motivado por distintos factores históricos, de los cuales uno de los principales (y más recientes) es la expedición de notables Constituciones posbélicas como rechazo a lo ocurrido en la Segunda Guerra Mundial. Sin embargo, conceptualizar a una Cons-

* El tema de la legitimidad y la justicia constitucional en relación con el argumento contramayoritario — en los términos de Bickel — ha sido uno de mis intereses durante largo tiempo. El presente artículo nace de una estancia de investigación realizada en el Instituto de Investigaciones Jurídicas de la UNAM en 2009. Algunas de las ideas contenidas fueron plasmadas con una perspectiva diversa en mi artículo "The Countermajoritarian Difficulty: Bickel and the Mexican Case", actualmente aceptado en Mexican Law Review. Agradezco a Diego Valadés y Eduardo Ferrer Mac-Gregor por discutir algunas de las ideas contenidas en este artículo. De igual forma un agradecimiento a Efrén Chávez por su clara guía bibliográfica en torno a los conceptos de representación y crisis política. Finalmente no puedo dejar de agradecer los valiosos comentarios sobre el borrador del presente trabajo a mis colegas y amigos José Rueda Reyes y Ubiliado Domínguez. Agradezco al comité editorial de Cuestiones Constitucionales las valiosas observaciones hechas al presente trabajo.

1 La misma idea de Constitución ha cambiado a raíz de la concepción neoconstitucionalista y sus funciones distan de ser orgánicas para posarse como centro del ideario estatal. Para un estudio de las funciones de los textos constitucionales en el Estado moderno, véase Häberle, Peter, El Estado constitucional, Buenos Aires, Astrea, 2007, pp. 220-230. De igual forma para las funciones de la Constitución, cfr., Valadés, Diego, Constitución y democracia, México, UNAM, Instituto de Investigaciones Jurídicas, 2002, pp. 107-111.

2 El Estado constitucional es en sí un ideario a alcanzar, Ruiperez ha descrito con acierto la historia del moderno Estado constitucional y hacia él nos remitimos, véase Ruipérez, Javier, El constitucionalismo democrático en los tiempos de la globalización, México, UNAM, Instituto de Investigaciones Jurídicas, 2005, pp. 63-134. 
titución como el centro de la vida requiere mecanismos que restauren el orden constitucional cuando éste ha sido perturbado. No es extraño por tanto, que la importancia otorgada a la jurisdicción constitucional haya aumentado enormemente en estos últimos años y que el derecho procesal constitucional juegue un papel relevante en la ciencia jurídica contemporánea.

Frente a este papel, numerosos opositores han intentado deslegitimar a la justicia constitucional acusándole de tener un carácter fuertemente antidemocrático y elitista, así como el de ser un elemento discrecional en favor del Poder Judicial del tribunal o sala constitucional, según sea el caso. Esta acusación es denominada a grandes rasgos argumento contramayoritario y será el tema de discusión en este artículo. En el apartado segundo se emprende un estudio breve de la decisión Marbury vs. Madison y se hace una reseña del surgimiento y condiciones de la crítica contramayoritaria. En la sección tercera se introduce una distinción de tipos contramayoritarios y se hace un acotamiento del concepto de representatividad. En la sección cuarta se discute ampliamente los diferentes argumentos esgrimidos en favor y en contra de la justicia constitucional. En la sección final se realizan conclusiones abogando por una cofundamentación de la legitimidad de la justicia constitucional en torno a la defensa de derechos procedimentales, minoritarios y el aseguramiento de la vigencia efectiva constitucional.

\section{JUDICIAL REVIEW Y CONTRAMAYORÍA}

Podemos detectar dos momentum en la expansión de la denominada justicia constitucional. El primero de ellos es la decisión Marbury vs. Madison en 1803, en la cual se estableció la supremacía constitucional por la Suprema Corte de Estados Unidos, estudiaremos con posterioridad esta decisión en forma más detenida. El segundo gran detonante puede ser detectado en 1920 cuando el Tribunal Constitucional austriaco comenzó a operar bajo el diseño kelseniano. Una de las principales diferencias entre ambos acontecimientos puede ser indicada por el hecho de que mientras el Tribunal Constitucional kelseniano fue producto de una meditada discusión ${ }^{3}$ acerca

3 El debate acaecido entre Kelsen y Schmitt ha sido una de las discusiones más polémicas y productivas en la teoría constitucional. Para una descripción detallada de esta discusión véase el primer capítulo de Gianformaggio, Letizia, Estudios sobre Kelsen, 
del custodio de la Constitución ${ }^{4}$ — y en gran medida una cuidadosa creación académica-Marbury vs. Madison fue el resultado de la doctrina constitucional, jurisprudencia y política.

Marbury vs. Madison ha sido una decisión ampliamente estudiada y analizada. No pretenderemos realizar en este breve artículo lo que otros ya han hecho con mucha mayor precisión; 5 sin embargo, el argumento contramayoritario es originalmente esgrimido por Bickel en contra ${ }^{6}$ del Judicial Review y entender la naturaleza de su surgimiento puede ayudar a comprender su naturaleza constitutiva .

El nombramiento de John Marshall como Chief Justice de la Suprema Corte estadounidense fue una clara medida tomada por Adams para limitar la capacidad política de Thomas Jefferson ante su inminente ascenso al poder. Más aún, poco antes de realizar el cambio de administración el congreso federalista promulgó el Acta Judicial de 1801 que, entre otras cosas, expandió el número de cortes de circuito, redujo el número de ministros de la Suprema Corte y le permitió al presidente per se nombrar jueces de paz y jueces federales con lo que se incrementó considerablemente la jurisdicción federal estadounidense. Sin embargo, este aumento se tradujo en que el número de vacantes disponibles fuese tan alto que el gobierno de Adams no pudo entregar todas las comisiones en el tiempo indicado y asumió simplemente que el nuevo secretario de Estado (Ja-

México, Fontamara, 2002. Gianformaggio hace una clara distinción entre las ideas de Schmitt y las ideas kelsenianas.

4 El ensayo "La garantía jurisdiccional de la Constitución" pretendía responder a la pregunta Wer soll der Hüter der Verfassung sein?, véase Kelsen, Hans, La garantía jurisdiccional de la constitución, trad. de Rolando Tamayo, México, UNAM, 2001.

5 La bibliografía es inmensa. Entre otros véase Kelly, M. R, "Marbury vs. Madison: An Analysis", High Court Quarterly Review, Estados Unidos, vol. 1, núm. 2, 2005, pp. 58-141, que explica el impacto de la decisión (58-69); Yoo, John y Prakash, Saikrishna, "The Origins of Judicial Review", University of Chicago Law Review, Estados Unidos, vol. 69, 2003, pp. 887-982, que describe la importancia del Judicial Review para la adjudicación constitucional y la moderna conceptualización de este control jurisdiccional; para una versión en español del multicitado fallo véase Cienfuegos, David (coord.), Marbury contra Madison: una decisión histórica para la justicia constitucional, México, Laguna, 2005, pp. 175-203.

6 Debemos ser cuidadosos con esta afirmación. La obra de Bickel "The Least Dangerous Branch" de la cual nace formalmente el argumento contramayoritario, es concebida por Bickel como una defensa del Judicial Review. 
mes Madison) las entregaría. ${ }^{7}$ Una de estas comisiones, que no pudo ser entregada a tiempo, correspondía a William Marbury, un fuerte seguidor de las ideas de Adams y que recientemente había sido designado juez de paz en el distrito de Columbia. Ahora bien, cuando Jefferson entra al poder, en un intento de contrarrestar las medidas tomadas por Adams, el gobierno jeffersoniano se negó a entregar las comisiones a su vez mediante una triquiñuela legal: la expedición del Acta Judicial de 1802 por parte del Congreso republicano. Sin embargo, cuando William Marbury demandó sus derechos en la Corte mediante un writ of mandamus, la propia Suprema Corte y en particular John Marshall, enfrentaron un terrible dilema. ${ }^{8} \mathrm{O}$ bien decidían a favor de Madison (una alineación con la ideología política dominante), o bien, decidían a favor de Marbury, en el entendido de que su decisión sería difícilmente efectiva o ejecutable y probablemente ignorada por Thomas Jefferson, lo cual pondría a la propia autonomía de la Corte y su papel como guardián último de la legalidad en peligro. El resto es historia. La Corte declaró inconstitucional y por tanto sin fuerza ni ejecutividad la sección 13 del Acta Judicial de 1789, la cual daba a la Corte jurisdicción para conocer del writ of mandamus bajo el argumento de que esta norma secundaria otorgaba facultades a la Corte que sobrepasaban las establecidas originalmente por la Constitu-

7 La intención de bloquear el gobierno de Jefferson por parte de Adams era meridianamente manifiesta. Cuando John Marshall fue nombrado Chief Justice de la Suprema Corte todavía desempeñaba las funciones de secretario de Estado de Adams.

8 Recordemos que lo que demandaba Marbury era obligar al secretario de Estado, Madison, a entregarle la comisión que previamente el propio John Marshall le había asignado mientras fungía como secretario de Estado de Adams. Para una estudio sucinto de la controversia véase Rivera León, Mauro Arturo, "Judicial review y justicia constitucional: algo de historia”, Revista Universidad de Sonora, Sonora, México, núm. 27, octubre-diciembre de 2009, pp. 18-20.

9 Gargarella sostiene que la Judiciary Act de 1789 era una forma de reafirmar que la interpretación constitucional era privativa de la Corte, una forma de colocar la Corte como guardián constitucional último. Si la afirmación de Gargarella es correcta, resulta entonces paradójico que la forma que tuvo la Corte Marshall de afirmarse como último intérprete constitucional fue la anulación de una sección de esta misma acta. Véase Gargarella, Roberto, Los fundamentos legales de la desigualdad, España, Siglo XX1, 2005, p. 229. 
ción. ${ }^{10}$ Aquí, en las palabras de John Marshall, había nacido la institución del Judicial Review:

So, if a law [e. g., a statute or treaty] be in opposition to the Constitution, if both the law and the Constitution apply to a particular case, so that the Court must either decide that case conformably to the law, disregarding the Constitution, or conformably to the Constitution, disregarding the law, the Court must determine which of these conflicting rules governs the case. This is of the very essence of judicial duty. If, then, the Courts are to regard the Constitution, and the Constitution is superior to any ordinary act of the Legislature, the Constitution, and not such ordinary act, must govern the case to which they both apply. ${ }^{11}$

Al declarar la inconstitucionalidad de la sección 13 del Acta Judicial de 1789 la Corte carecía entonces de competencia ${ }^{12}$ para conocer el asunto y por lo tanto no tuvo que resolver en sentido alguno. William Marbury nunca fungió como juez de paz del distrito de Columbia.

Sin embargo, el reconocimiento del Judicial Review y su implementación en la práctica constitucional estadounidense no vino sin dificultades. ¿Cómo era posible que la voluntad de algunos cuantos ministros se im-

10 Sobra decir que Jefferson estuvo en desacuerdo con la Corte, no por el resultado provocado por la decisión, sino por la decisión misma. En la opinión de Jefferson, el defender tal doctrina sería instituir un gobierno de hombres sobre un gobierno de leyes. Jefferson era un demócrata popular y poseía mucha más fe en las capacidades decisorias del pueblo que su contraparte Adams y por supuesto pensaba que la simple inclusión de mecanismos de democracia directa mejoraban sustancialmente la democracia. El desacuerdo de Jefferson con la decisión de la Corte no se basó en una razón jurídica o una teoría personal del derecho constitucional sino en un desacuerdo profundo acerca del verdadero significado de la palabra democracia.

115 U.S. at 177-78. Las itálicas son mías.

12 Existen autores que creen que la decisión fue pragmática. Bajo esta perspectiva la Corte no encontró una norma inconstitucional o por lo menos no desde un punto de vista sincero. Marshall desde un inicio buscó el evitar pronunciarse sobre el asunto, lo que lo llevó a determinar que la inconstitucionalidad de la norma aludida lo exoneraría de tener que tomar una decisión, en palabras de Nelson: "Thus, Marshall had to find a way to deny Marbury the writ of mandamus", véase Nelson, William, Marbury vs. Madison: The Origins and Legacy of Judicial Review, Estados Unidos, University Press of Kansas, 2000, p. 63. 
pusiese a la de los legítimos representantes del pueblo norteamericano? ${ }^{13}$ ¿Era legítima esta injerencia del Poder Judicial dentro de una esfera que era competencia del Legislativo? ¿Acaso no atentaba el Judicial Review contra el carácter democrático?

$\mathrm{El}$ argumento contramayoritario es entonces aquella imputación hecha inicialmente al Judicial Review — y actualmente a la jurisdicción constitucional- del carácter antidemocrático de sus decisiones. Es una crítica planteada en términos de principios mayoritarios, democracia, legitimidad y carencia de representatividad.

La versión más clara y elaborada de esta counter-majoritarian difficulty fue hecha por Alexander Bickel en su libro The Least Dangerous Branch: The Supreme Court at the Bar of Politics, obra hecha como una defensa del Judicial Review. Bickel consideraba que Marshall había argumentado incorrectamente que la Constitución era la expresión máxima de la soberanía y que cuando la Corte invalidaba una norma secundaria sólo hacía prevalecer la voluntad popular expresada en la Constitución. De tal suerte, si sólo se considerase a la Corte como un legislador negativo $^{14}$ sería más sencillo compaginar su naturaleza antidemocrática, pues limitaría su discrecionalidad. El argumento era racional pero tenía inconsistencias. No todas las contradicciones entre una norma ordinaria y la Constitución eran manifiestas y el juez por tanto no era un simple autó-

13 Una figura empleada con frecuencia, "At the practical level of implementation the specific consequences of venerating the Constitution in America is the power it gives the US Supreme Court. Nine elders appointed for life by the president, with the consent of the Senate, have become in a very real sense, the final arbiters for legitimacy of the American State". Riggs, Fred, "Presidentialism versus Parliamentarism: Implications for Representativeness and Legitimacy”, International Political Science Review, Estados Unidos, vol. 18, núm. 3, 1997, p. 271.

14 Véase Cossío Díaz, José Ramón, "Los tribunales constitucionales y la división de poderes", Ciencia. Revista de la Academia Mexicana de la Ciencia, México, vol. 58, núm. 4, 2007, pp. 79-86. En lo particular Cossío acierta cuando afirma (p. 83): "No aceptamos, probablemente por un recato, decir: 'pues no somos legisladores negativos, porque no sólo expulsamos normas, sino que le damos sentido operativo a la Constitución', pero tampoco aceptamos estar en una condición de legisladores positivos en su sentido integral completo... De cualquier modo, la función directa de legislador negativo no es tan difícil de compaginar con la naturaleza democrática del Estado constitucional, es más bien la anulación de normas en base a controversiales interpretaciones que frecuentemente requieren una lectura moral de la constitución la que provoca la polémica contramayoritaria". 
mata que aplicaba el método de subsunción en cada caso constitucional: el juez interpretaba y el Judicial Review podía ser controversial. De esta forma, Bickel argumentaba que cuando la Corte ejercía el Judicial Review este control no era ejercido "in behalf the prevailing majority, but against it". ${ }^{15} \mathrm{El}$ entendimiento de Bickel del carácter contramayoritario era excepcional e indudablemente fue el argumento más claro y lúcido planteado en términos democráticos presentado en mucho tiempo contra el Judicial Review. Ahora bien, aun cuando sea elogiable la claridad conceptual y la elocuencia con la que Bickel presentó lo que denominó counter-majoritarian difficulty (un eufemismo para antidemocrático de acuerdo a Posner), este entendimiento era comprensible. Para 1962, fecha en la cual Bickel publicó su obra, la Suprema Corte había producido suficientes decisiones controversiales y polémicas para llamar la atención de académicos, juristas, miembros del Poder Judicial y de la sociedad en general. ${ }^{16}$ Entre otras, algunas de estas decisiones fueron Marbury vs. Madison, ${ }^{17}$ Dread Scott vs. Standford, ${ }^{18}$ las decisiones en contra de

15 Bickel, Alexander, The Least Dangerous Branch: The Supreme Court at the Bar of Politics, 2a. ed., Estados Unidos, Bobbs-Merril, 1962, pp. 16 y 17.

16 Es bueno recordar que el propio Alexander Bickel se desempeñó como law clerk bajo la tutela del ministro Frankfurter.

175 US. (1 Cranch) 137 (1803). Esta decisión constituye la más importante decisión tomada por una corte en todo el continente americano. Quizás para el caso Europa la decisión sería Van Gend en Loos [1963] ECJ (Van Gend en Loos v. Nederlandse Administratie der Belastingen), que de forma última estableció el conocido criterio Van Gend.

1860 U.S. (19 How) 393(1856). Un decisión que tuvo consecuencias políticas sumamente importantes y que contribuyó de forma indubitable a la detonación de la Guerra Civil estadounidense. La crítica de esta decisión fue intensa - sobre todo en el norte - y por supuesto fue puesta en términos contramayoritarios. Incluso si ignoramos el hecho de la deficiencia argumentativa de la Corte (que sostuvo que ningún negro o descendiente de negros era ciudadano y que por tanto no tenía derechos constitucionales), esta decisión sólo fue respaldada por una parte restringida de la población estadounidense y era por tanto materialmente contramayoritaria. Véase Weinberg, Louis, "Dread Scott and the Crisis of 1860", Chicago Kent Law Review, Estados Unidos vol. 82, núm. 1, 2007, pp. 97-139, que básicamente argumenta la contribución de Dread Scott vs. Standford a la Guerra civil. De igual manera véase Finkleman, Paul, "Teaching Slavery in Constitutional Law", Akron Law Review, Estados Unidos, vol. 34, núm. 1, 2000, pp. 261-282; Finkleman (262) llama a Dread Scott vs. Standford "the most politically divisive decision of the Supreme Court in our history". Finalmente Nelson, William, op. cit., nota 14, p. 70 , donde se afirma que Dread Scott vs. Standford fue la primera gran decisión (después de Marbury vs. Madison) en la cual la Corte invalidó política legislativa que había sido 
Roosevelt que invalidaban legislación del New Deal ${ }^{19}$ (y por supuesto el incidente del Court-Packing Plan), ${ }^{20}$ Brown vs. Board of Education ${ }^{21} \mathrm{y}$ finalmente la decisión Baker vs. Carr, ${ }^{22}$ entre otras. La mayoría de estos casos presentaban las características necesarias para desatar una discusión en términos contramayoritarios. Eran casos polémicos, que habían despertado controversia y respecto a los cuales tanto los órganos repre-

votada por una mayoría nacional sustancial y a la cual muchos electores aún presentaban adhesión.

19 Este tema es tan extenso, que tratar de explicarlo de forma detallada requeriría en sí mismo un extenso trabajo. Franklin Delano Roosevelt fue el trigésimo segundo presidente de los Estados Unidos (1933-1945) y trató de contrarrestar la gran depresión americana con una serie de políticas denominadas New Deal. La Corte invalidó sistemáticamente toda la legislación del New Deal al declararla inconstitucional, lo cual derivó en una confrontación abierta entre la Corte y Roosevelt y en numerosos intentos de este último para minar la autonomía de la Corte (principalmente el infructuoso Court-Packing Plan de 1937). Como resultado indirecto de estos intentos, la Corte se tornó más tolerante con la legislación del New Deal y lentamente revirtió sus decisiones una por una. Es curioso el pensar que Roosevelt haya sido el único presidente en reelegirse más de dos veces (cuatro periodos consecutivos). Para el momento en que abandonó la Presidencia, Roosevelt había nombrado a ocho de los nueve ministros de la Suprema Corte. En el primer mandato de Roosevelt las imputaciones del carácter antidemocrático de la Corte eran frecuentes.

20 Véase Friedman, Barry, "The History of the Countermajoritarian Difficulty Part Four: Law's Politics", University of Pennsylvania Law Review, Estados Unidos, vol. 148, núm. 4, 2000, pp. 971-1064, en lo particular véase 973-981, en donde Friedman con rigor histórico hace una comparación de la legislación del New Deal, el Court-Packing Plan y los enfrentamientos entre Roosevelt y la Suprema Corte y las razones por las cuales el Court-Packing Plan falló (en cierto sentido).

21347 U.S. 483 (1954). Esta decisión ha sido considerada decisiva de la Corte Warren. Para un estudio a fondo véase Delgado, Richard y Stefancic, Jean, "The Racial Double Helix: Watson, Crick and Brown vs. Board of Education", Howard Law Journal, Estados Unidos, vol. 47, 2004, pp. 476-498, en donde se argumenta la importancia de la decisión y se compara (476) a ésta con el descubrimiento del ADN. Para un relato político de la toma de la decisión y la contribución respectiva de los ministros Vinson (que finalmente moriría antes de decidir), Frankfurter y el propio Warren, véase Tushnet, Mark y Lezin, Katya, "What Really Happened in Brown vs. Board of Education", Columbia Law Review, Estados Unidos, vol. 91, núm. 8, 1991, pp. 1867-1931. A pesar de que la decisión en sí misma es progresista, la discusión fue acalorada, ministros como Burton todavía pensaban en términos raciales, categorizando, por ejemplo, a los mexicanos como "the mexican problem...beacause the mexicans were more retarded...", p. 1908.

22369 U.S. 186 (1962). Decision que calificó de justiciables (cumplimiento de los justiciability requirements) los casos de reacomodo distrital electoral (reapportionment). 
sentativos como el electorado habían manifestado cierta opinión y las decisiones de la Corte habían ido formal o materialmente en contra de estas mayorías. Por supuesto, algunas decisiones como Brown vs. Board of Education estuvieron exentas de críticas contramayoritarias dado que una parte sustancial del electorado apoyó directamente esta decisión y por tanto la crítica hacia ella tuvo que ser formulada en un lenguaje diferente al democrático. Sin embargo, ciertas decisiones fueron contramayoritarias de una forma innegable, por ejemplo Dread Scott vs. Standford y las concernientes a la invalidación de legislación del New Deal. Tales decisiones fueron objeto de una importante crítica que hizo a los norteamericanos conceptualizar nuevamente el papel de su Corte y repensar su función dentro del sistema democrático.

Sin embargo, debemos entender la causa del excesivo enfoque en las decisiones contramayoritarias tomadas por jueces, cortes o tribunales. Una decisión contramayoritaria puede no necesariamente ser judicial, ${ }^{23}$ puesto que, de acuerdo al órgano que la emite, podemos diferenciar tres tipos de decisiones contramayoritarias: $a$ ) decisiones contramayoritarias legislativas, b) decisiones contramayoritarias administrativas, y c) decisiones contramayoritarias jurisdiccionales. ${ }^{24}$

Ejemplos de decisiones contramayoritarias legislativas son todas aquellas normas que hayan sido aprobadas por los congresos o parlamentos aun cuando el electorado materialmente desapruebe la ley determinada. ${ }^{25}$ Por otra parte, las decisiones contramayoritarias administrativas

23 Ides parece concordar cuando afirma que “...judicial review is no more antidemocratic than a whole host of constitutional provisions: bicameralism, presidentialism veto, federalism, the composition of the Senate, etcetera". Ides, Allan, "The American Democracy and Judicial Review”, Arizona Law Review, Estados Unidos, vol. 33, 1991, p. 41.

24 Podemos suponer que para efectos prácticos en aquellos órdenes jurídicos en donde el Tribunal Constitucional se encuentre fuera del aparato jurisdiccional como en la conceptualización original de Kelsen, estas decisiones serían categorizadas como contramayoritarias en un sentido jurisdiccional. Nos apartaremos de considerar aquellas decisiones contramayoritarias por parte de organismos constitucionalmente autónomos o no gubernamentales. Quizá se pudiesen añadir a las categorías mencionadas las decisiones contramayoritarias metatripartitas - aquellas hechas por órganos del Estado o constitucionalmente autónomos fuera de la división de poderes - y decisiones contramayoritarias civiles, pero dicha distinción no es necesaria para el presente trabajo.

25 La hipótesis es sencilla de suponer. Una norma la cual elevase sustancialmente - e innecesariamente - el presupuesto de los partidos políticos podría contar con la 
son aquellas tomadas en contra de determinaciones de la mayoría formal representativa (como una mayoría en el Congreso) o bien de la mayoría electoral material (las preferencias populares). Un ejemplo claro de la primera figura lo constituye el veto, cualquier determinación discrecional de carácter administrativo repudiada por los electores constituye un ejemplo de la segunda. Finalmente, los ejemplos de la contramayoría jurisdiccional son innecesarios.

Ahora bien, consideremos momentáneamente el grado de atención recibido por los tres distintos tipos de contramayoría. ¿Por qué la contramayoría jurisdiccional ha recibido sustancialmente mayor atención que la contramayoría legislativa o administrativa? ¿Acaso sus repercusiones antidemocráticas son mayores? ${ }^{26}$

El caso de la contramayoría administrativa es ejemplar en este respecto. La atención a la counter-majoritarian difficulty no radica de forma exclusiva en su carácter contramayoritario. Si ese fuera el caso entonces el veto del Ejecutivo ${ }^{27}$ habría recibido cuando menos una atención similar. Esta focalización tampoco se encuentra basada en la dificultad de revertir las decisiones contramayoritarias jurisdiccionales pues entonces la contramayoría legislativa habría sido estudiada con mayor profundidad. A nuestro juicio esta atención se encuentra basada en la deficiencia de

aprobación de todos los representantes populares en las cámaras, pero obviamente sería desaprobada por el electorado general. Tal decisión sería considerada contramayoritaria (en el sentido material aquí empleado) en sentido legislativo. Lo curioso es que comúnmente no existen medios de revocar este tipo de leyes y, en lo que a nosotros concierne, la contramayoría legislativa es la más complicada de contrarrestar. La contramayoría jurisdiccional se elimina mediante una reforma a la ley o a la Constitución; la contramayoría administrativa con distintos procedimientos contencioso-administrativos o bien en el caso del veto con la figura de la insistencia. ¿Qué procede en el caso de la contramayoría legislativa?

26 Debo algunas de estas consideraciones a Diego Valadés, quien ha argumentado la peculiaridad inherente en las decisiones contramayoritarias jurisdiccionales con respecto a la figura del veto.

27 Este asunto merece cuidadosas consideraciones. Para un estudio pormenorizado del veto en relación con la mencionada figura de la insistencia, véase Alcántara Sáez, Manuel y Sánchez López, Francisco, "Veto, insistencia y control político en América Latina: una aproximación institucional", Perfiles Latinoamericanos, México, año 10, vol. 9, 2001, pp. 153-177. 
legitimidad de origen de los jueces con respecto a las legislaturas o los poderes ejecutivos. ${ }^{28}$

Ahora bien, la crítica contramayoritaria emerge en determinados contextos y ante determinadas decisiones. ${ }^{29}$ De acuerdo con el análisis de Friedman, ${ }^{30}$ la crítica ante decisiones contramayoritarias de una corte se presentan ante la presencia de cuatro importantes factores, a saber:

1. La impopularidad de una decisión ante un grupo sustancial capaz de alegar que habla por "las personas" o por una mayoría;

2. La determinada concepción democrática imperante (una visión que en mayor medida favorezca la democracia directa);

3 . El grado de determinación ${ }^{31}$ que se presuma en los preceptos constitucionales, y

4. Que tales decisiones hayan sido tomadas en momentos de verdadera supremacía constitucional.

Esta última observación por parte de Friedman es increíblemente acertada. La supremacía constitucional material y efectiva es un requisito sine qua non para la crítica contramayoritaria. En ausencia de esta supremacía las decisiones pueden ser ignoradas y por tanto no tendrán

28 A pesar de que una gran cantidad de jueces constitucionales son electos por conjunción del Ejecutivo y el Legislativo, es obvio que su legitimidad se deriva de la legitimidad de los agentes primarios que lo designan y en tal aspecto, su legitimidad es secundaria, derivada y menor.

29 Es importante recordar que Friedman muestra las circunstancias en las cuales la crítica contramayoritaria, pero no las razones.

30 Friedman, Barry, "The History of the Countermajoritarian Difficulty, Part One: The Road to Judicial Supremacy", New York University Law Review, Estados Unidos, vol. 73, núm. 2, 1998, p. 342.

31 En este punto me encuentro en desacuerdo con Friedman. Sostengo que la formación de una teoría coherente de interpretación constitucional que pueda presuponer encontrar o asignar un sentido correcto a un precepto constitucional es innecesario. Basta con que los críticos representen un punto de vista interpretativo o asignen determinado significado al precepto constitucional y crean que un grupo sustancial del electorado (i. e. mayoría) asignan a éste el mismo sentido (de lo contrario la crítica sería teóricointerpretativa, no contramayoritaria). Por tanto, es posible encontrar crítica contramayoritaria aun cuando pueda presuponerse que el precepto es relativamente vago, basta con que la interpretación mayoritaria presuma un significado, y el significado asignado por la decisión judicial difiera sin una causa justificada al asignado por el grupo en cuestión. 
una interferencia real con la pretendida voluntad mayoritaria. La crítica contramayoritaria no es una crítica planteada en aspectos teóricos sino esencialmente pragmática. La crítica se desata como rechazo directo al resultado, no al método obtenido. Inclusive si Brown vs. Board of Education hubiese sido decidido en un contexto formal y materialmente contramayoritario, una gran cantidad de académicos y estudiosos habrían alabado la decisión. Gran parte de la deferencia a realizar argumentación contramayoritaria en México se ha debido a la ausencia histórica de una supremacía constitucional en sentido fuerte.

De igual manera, Víctor Ferreres Comella detecta las razones por las cuales surgen objeciones contramayoritarias (a diferencia de Friedman que estudió las circunstancias contextuales de las decisiones contramayoritarias que favorecen la crítica misma). El análisis de Ferreres se basa en tres razones: la menor legitimidad democrática de origen del juez constitucional, la rigidez de la Constitución (y la consecuente imposibilidad del legislativo de revertir con facilidad decisiones contramayoritarias), y la controvertibilidad interpretativa de la Constitución. ${ }^{32}$

32 Ferreres Comella, Víctor, Justicia constitucional y democracia, Madrid, Centro de Estudios Políticos y Constitucionales, 1997, p. 42. Ahora bien, aun cuando Ferreres sostenga que "A mi juicio, las circunstancias que dan lugar a la 'dificultad contramayoritaria’ son la tres siguientes...”, me parece que quizás confunde las circunstancias de aparición de la crítica contramayoritaria - como las analizadas por Friedman- con las razones mismas de la objeción contramayoritaria. Los cuatro elementos propuestos por Friedman son circunstanciales y dúctiles - al ser circunstancias pueden variar en grado- mientras que los propuestos por Ferreres se asemejan mucho más a razones y las tomo por tales. ¿Acaso Ferreres sostiene implícitamente que la menor legitimidad democrática de origen del juez es circunstancial? Es decir ¿puede variar conforme al tiempo? A menos que Ferreres presuponga variaciones en el método de elección del juez constitucional su primer punto no es circunstancial. Su segunda circunstancia es la rigidez de la Constitución, y a menos que nuevamente presupongamos que Ferreres distinguió entre rigidez material y formal (distinción que Ferreres no introduce ni presupone) nuevamente es una causal no una circunstancia. Finalmente, la controvertibilidad interpretativa de la Constitución puede ser considerada circunstancia si atendemos a los diferentes criterios interpretativos imperantes que pueden de forma variada considerar mayor o menormente controvertible un precepto. Empero, si atendemos a los criterios objetivos normativos ( $i$. $e$ indeterminación semántica, vaguedad del precepto, principios constitucionales) podría ser considerada de igual forma como una razón. Para un estudio interpretativo de la óptica de Ferreres, véase Caamaño Domínguez, Francisco, "Los vértices de la desconfianza: Constitución, ley y juez", Revista Española de Derecho Constitucional, España, año 2, núm. 65, mayo-agosto de 2002, pp. 387-396. 
En esta sección analizamos brevemente el surgimiento del Judicial Review y realizamos un análisis conceptual del argumento contramayoritario, así como alguna de sus implicaciones, circunstancias de surgimiento y razones de su manifestación. En la sección siguiente se analizará con mayor profundidad algunos de los argumentos esgrimidos en pro y en contra del carácter antidemocrático del control jurisdiccional mediante el análisis del argumento contramayoritario como punto de partida. Se intentará mostrar que la fundamentación de la legitimidad de la jurisdicción constitucional no puede encontrarse individualmente en una argumentación sino en una cofundamentación de argumentos.

\section{DISTINCIONES: REPRESENTATIVIDAD Y CONTRAMAYORÍA}

Una decisión contramayoritaria es aquella tomada en contra de una mayoría determinada. Sin embargo, normalmente cuando decimos que una decisión de la corte es contramayoritaria, nos referimos a que atenta contra la voluntad de los representantes del pueblo y no del pueblo mismo. En esta sección esclareceremos brevemente el concepto de representación y ampliaremos la noción de contramayoría introduciendo los conceptos de contramayoría formal, material y concurrente.

La representación constituye una de las problemáticas del argumento contramayoritario. ¿Las preferencias populares se encuentran plasmadas realmente en la representatividad? ${ }^{33}$ La realidad es que las facciones políticas disminuyen considerablemente la representatividad de cualquier decisión. ${ }^{34}$ En cierta forma, la democracia estadounidense - en donde fue gestada la counter-majoritarian difficulty - fue pensada para ser no una democracia simple de mayorías, o una democracia de asambleas, sino una democracia relativamente ajena a las presiones netamente ma-

33 ¿Existe realmente responsabilidad política por parte de los diputados fuera del voto primario del cuál se desprende su legitimidad? ¿En cuántas democracias representativas existe algún control secundario preferencial de naturaleza no política? Las democracias representativas son, pues, ajenas a la simple decisión mayoritaria, ya que deben presuponer representación, pero en un sentido preferencial.

34 Pérez Johnston, Raúl, "Representación política, democracia, status quo; crisis de un sistema constitucional”, Iuris Tantum, México, tercera época, núm. 19, 2008, pp. 138 у 139 . 
yoritarias. ${ }^{35}$ Por ello, así como la noción de mayoría, la propia noción de representatividad esclarece los sentidos de las decisiones contramayoritarias. A pesar del ya clásico estudio de Pitkin, ${ }^{36}$ definiremos tres diferentes $\operatorname{conceptos}^{37}$ de representación útiles al estudio de la objeción contramayoritaria: 38

\section{Representación preferencial, que es la capacidad de transmisión exacta de opiniones, percepciones y preferencias.}

35 Esta es una explicación coherente al porqué se le dotó de tanta autonomía a un cuerpo representativo. Luego entonces bajo este modelo representativo es imposible sancionar a un representante por desviarse notoriamente de las preferencias del electorado representado. Véase sobre la naturaleza de la democracia estadounidense en referencia a la representación, Gargarella, Roberto, Crisis de representación política, México, Fontamara, 1997, pp. 93-95. En el mismo sentido, id., "Crisis de representación y constituciones contramayoritarias”, Isonomía, México, núm. 2, 1995, pp. 89-108.

36 Pitkin, Hanna Feinchel, El concepto de representación, trad. de Ricardo Montoro, Madrid, Centro de Estudios Constitucionales, 1995. El libro de Pitkin es muy incisivo respecto a la controversia mandato-independencia (pp. 156-183).

37 Existen otros conceptos de representación. Para una distinción en nuestra opinión acertada véase García Guitán, Elena, "Crisis de la representación política: las exigencias de la presencia”, Revista de Estudios Políticos, Madrid, nueva época, núm. 111, 2001, pp. 215-226 y en lo particular 215-217 sobre los distintos tipos de representación.

38 Por supuesto existen diversos tipos de representación a los aquí enunciados, pero los empleados en el presente trabajo son claves para el entendimiento de la countermajoritarian difficulty. Hernández comprende que en la democracia representativa el representante no es un simple delegado, sino un fiduciario que representa los intereses de la nación y en tanto tal, independiente. Véase Hernández de Gante, Alicia, "Crisis de representación política", Revista de Investigaciones Jurídico Politológicas, México, núm. 21-22, 2005, p. 361. Diego Valadés sostiene que la afirmación de la democracia como un sistema más allá de la simple asamblea de mayorías, se robustece de la lectura del preámbulo de la Constitución de Estados Unidos: "We the People of the United States, in order to form a more perfect Union". El texto reza "We the people" (nosotros el pueblo) no reza "We the majority of the people" (nosotros, la mayoría del pueblo). Por tanto, el concepto mismo de pueblo debe de ser estudiado para entender en nombre de quién actúa la democracia estadounidense. De tal suerte que representar al pueblo o nación es un concepto mucho más amplio - pero difuso - que representar a la mayoría electoral o a las mayorías del pueblo o nación. Cuando la Constitución de Estados Unidos fue promulgada, ¿we the people representaba a las mayorías electorales? ¿Representaba acaso un concepto de ciudadanía excluyendo indígenas, personas de color y mujeres? ¿O era un concepto vago e inclusivo? ¿Actualmente qué significa? El debate sigue abierto. 
2. Representación presupuesta, que es aquella en que se le otorga a individuos la potestad de tomar decisiones o emitir opiniones que suponen una representación preferencial.

3. Representación composicional, que es aquella en la que determinado cuerpo colegiado se integra para ser una exacta muestra no de las preferencias, sino de la composición misma mayoritaria, y

4. Representación mandato. El concepto bajo el cual una decisión es contramayoritaria es por lo general un concepto de representación presupuesta, no preferencial.

Una vez esclarecidos los sentidos en que puede ser empleada la representación y habiendo definido la representación preferencial y presupuesta en oposición a la representación composicional y representación mandato, sabremos identificar el tipo de representación empleada por distintos cuerpos colegiados. Antes de proseguir con el análisis de argumentaciones contramayoritarias relativas a la jurisdicción constitucional creemos necesario introducir una distinción que a nuestro juicio es indispensable para determinar la legitimidad de las decisiones contramayoritarias y que ha sido ignorada sustancialmente por la doctrina. Para ello emplearemos un pequeño ejemplo que evidenciará el sesgo electoral posible en una democracia determinada y nos servirá de base para proponer distintos tipos de decisiones contramayoritarias.

Supongamos un país " $\mathrm{X}$ " en donde el $60 \%$ de la población capaz de votar efectivamente vote en una determinada elección. Asumamos que existen tres partidos políticos: A, B y C. El partido A obtiene la victoria con un $40 \%$ de los votantes, los partidos B y C obtienen respectivamente el 30\% cada uno. Supongamos que el proceso legislativo del país " $\mathrm{X}$ " requiere una mayoría calificada ${ }^{39}$ en el proceso legislativo para la aprobación de una ley ordinaria, luego entonces el partido A puede en conjunción con un porcentaje reducido de otro partido aprobar legislación ordinaria. Ahora bien, supongamos que la legislatura de " $X$ " promulgue una ley "A.1" que a juicio de los partidos de oposición contraríe los preceptos constitucionales de la norma fundamental de "X". Estos dos partidos,

39 Utilizaremos a la mayoría calificada en lugar de la mayoría simple para el presente ejercicio, porque de esta forma será notorio que incluso con procedimientos agravados de votación legislativa, las preferencias reales del electorado siguen siendo inciertas. 
legitimados para interponer ${ }^{40}$ una acción abstracta de inconstitucionalidad, someten al conocimiento de la Suprema Corte la constitucionalidad de la norma. La resolución de la Corte declara inconstitucional la ley y la anula con efectos erga omnes.

Esta resolución es contramayoritaria en el sentido en el que académicos, juristas, miembros del Poder Judicial y otros estudiosos del derecho han utilizado la noción de contramayoría. ¿En verdad esta decisión es completamente contramayoritaria? ¿La decisión de la Corte Suprema de $\mathrm{X}$ va en contra de toda preferencia de la mayoría? Evidentemente lo es, por lo menos en el sentido en el que es comprendida dentro del sistema electoral representativo (y por tanto en el sentido clásico de contramayoría). De hecho es un claro ejemplo de decisión contramayoritaria. La Corte Suprema de $\mathrm{X}$ ha anulado una norma promulgada por el Congreso con todas las características de validez y que ha pasado por el proceso formal de legislación instituido en la Constitución de X.

Sin embargo, debemos hacer ciertas consideraciones respecto a la decisión contramayoritaria tomada por la Corte. Primeramente consideremos el sesgo decisorio. En este caso, la norma fue aprobada por una mayoría simple en el Congreso. No obstante, esta norma cuenta con un sesgo de $40 \%$ del voto real posible, por lo que cae dentro de un umbral difuso en el cual es empíricamente imposible comprobar de forma conclusiva las preferencias del electorado ausente. Para promulgar la norma, el partido A debió haber obtenido un apoyo del 11\% del partido B (para obtener la mayoría necesaria). Aun cuando consideremos lo anterior, la norma ha sido aprobada con un $51 \%$ de apoyo efectivo, lo que representa apenas el $30.6 \%$ del electorado total posible a favor con un $29.4 \%$ del electorado total en contra y la subsistente zona de indeterminación del 40\%. Esta zona es vital para la distinción que elaboramos en este momento. Con dependencia en las preferencias reales — probablemente imposibles de

40 Sería curioso determinar, en el caso de la acción abstracta de inconstitucionalidad, quién ejerce la contramayoría. Por un lado, puede argumentarse que la decisión contramayoritaria es tomada en exclusivo por la Corte que declara inconstitucional una norma aprobada por la mayoría. Por otro, podría argumentarse que la facción minoritaria legislativa que interpone la acción abstracta de inconstitucionalidad ejerce una contramayoría también. En nuestra opinión la Corte ejerce la contramayoría dado que la facción minoritaria que impugna la norma ante el Tribunal Constitucional no toma per se una decisión contramayoritaria, sino que la solicita. Claro que puede sostenerse que la simple solicitud es en sí contramayoritaria, pero esto es sumamente argumentable. 
averiguar - de ese $40 \%$ podemos sostener que la decisión será contramayoritaria o no en un segundo sentido, diferente del usual. ${ }^{41}$

A partir de las consideraciones anteriores obtenemos una importante distinción: la contramayoría formal y la contramayoría material. ${ }^{42}$ Denomino contramayoría formal a aquellas decisiones que van en contra de procedimientos, legislación, determinaciones o cualesquiera otra acción ${ }^{43}$ basada en un consenso mayoritario presupuesto sistemáticamente y por tanto una noción presupuesta de representatividad. A contrario sensu, denomino contramayoría material a aquellas decisiones que van en contra de las percepciones mayoritarias reales ${ }^{44} \mathrm{y}$ efectivas de una

41 Es importante entender que los mecanismos electorales y en general aquellos designados para la emisión de la voluntad tiene por objetivo la real emisión de voluntad. Esta afirmación aparentemente tautológica no es tan sencilla como parece. Por ejemplo, cuando un votante (por desconocimiento de la correcta manera de llenar una boleta electoral) emite un voto nulo o inválido, esta nulidad del voto distorsiona la percepción mayoritaria. Su voto no contó y por tanto existirán porcentualmente (aun cuando sea en mínimas cantidades) facciones políticas sub o sobre representadas. Entre mayor sea el desfase entre la realidad mayoritaria y la percepción representativa, las decisiones legislativas serán menos mayoritarias en un sentido material. Existen diversos factores que causan este desfase, uno de ellos (realmente importante) es el abstencionismo. Si suponemos un abstencionismo radical del 95\%, ¿existirá legitimidad real en las decisiones de la mayoría? ¿Anular leyes de una legislatura legitimada máximo por el 5\% del electorado real y efectivo producirá decisiones contramayoritarias? Por supuesto que sí; la democracia representativa presupone una representación efectiva, pero esta decisión será contramayoritaria en un sentido forma y no material. De ser posible la emisión de la voluntad sería hecha sin errores, sin desviaciones, sin desfasamientos. Si fuese posible emitir la voluntad con el solo pensamiento y que esta voluntad fuese expresada numéricamente, tendríamos la voluntad del 100\% del electorado expresada sin error alguno. Un mecanismo tan perfecto es imposible y por ende la representación debe ser presupuesta.

42 Debo el refinamiento de estos conceptos y la clarificación de los mismos a dos estimados colegas: Ubiliado Domínguez y José Reyes Rueda.

43 Para la presente distinción no restringiré el concepto decisorio a la adjudicación judicial pues presupondré la existencia de distintos tipos de decisiones contramayoritarias. El veto del ejecutivo es un excelente ejemplo de una decisión que puede ser contramayoritaria en un sentido formal o material. El ejecutivo puede vetar una norma y por ello realiza una acción contramayoritaria en sentido formal; pero si las percepciones reales de la mayoría electoral respaldan la decisión, cuando menos materialmente, ésta no fue contramayoritaria.

44 "Similarly, we might try to understand whether judicial review really is countermajoritarian, and how it interacts with public opinion. In order to answer this question we need to know the extent to which Supreme Court decisions actually do deviate from 
población determinada de la cual se presupone una representación preferencial (coincida o no con las percepciones reales y efectivas). Finalmente, me parece necesario introducir un tercer concepto denominado contramayoría concurrente, que es la contramayoría resultado de la conjunción de los supuestos contramayoritarios anteriores.

De tal suerte, es posible entonces encontrar una decisión que sea contramayoritaria en un sentido formal pero no material; por ejemplo, la declaración de inconstitucionalidad por parte de un tribunal constitucional de una norma promulgada por una aplastante mayoría en el Congreso pero aprobada por cuestiones políticas y que sea repudiada evidentemente por el electorado. De igual forma es posible encontrar una decisión contramayoritaria en un sentido materia ${ }^{45}$ pero no formal (cuando el legislativo promulga la norma mencionada en el supuesto anterior). En este caso la decisión de promulgar la norma es contramayoritaria materialmente ya que va en contra de los deseos de la mayoría efectiva. Finalmente es posible encontrar una decisión contramayoritaria concurrente cuando dicha decisión va en contra de una mayoría formal y material; por ejemplo, cuando una corte anula una norma promulgada por una mayoría en el Congreso que simultáneamente es respaldada por una efectiva mayoría del electorado total. Esta distinción se basa por supuesto en una distinción presupuesta de decisiones mayoritarias. El determinar cuándo una decisión es verdaderamente mayoritaria es esencial para entender cuándo una decisión es materialmente contramayoritaria. Desconocemos una elaborada distinción de la doctrina de la contramayoría formal y material que hemos introducido, pero existen por el contrario, concepciones en términos parcialmente análogos para el caso de las decisiones mayoritarias. ${ }^{46}$

popular opinion, and on what issues, if any, this is most common", Friedman, Barry, "The History of the Countermajoritarian Difficulty Part Five: The Birth of an Academic Obsession", The Yale Law Journal, Estados Unidos, vol. 112, núm. 2, 2002, p. 257.

45 En el caso del control constitucional o concretamente del Judicial Review, normalmente las decisiones contramayoritarias materiales (declaración de inconstitucionalidad de una norma materialmente sustentada por el electorado) viene acompañada de una contramayoría formal, lo que hace a la decisión encuadrar en nuestro criterio de contramayoría concurrente.

46 Véase el paradigmático ejemplo de Ackerman, Bruce, We the People: Foundations, Inglaterra, The Benknap Press of Harvard University Press, 1993. Ackerman utiliza un concepto denominado "dualist democracy" para distinguir entre decisiones legislativas 
Las contramayorías material y formal son imperfectas mientras que la contramayoría concurrente es una contramayoría perfecta y conclusiva.

Comprendo que la distinción que he ofrecido con anterioridad no es una distinción sencilla de sostener y que puede presentar problemas prácticos considerables. ¿Cómo podemos determinar con exactitud el tipo de contramayoría al que nos enfrentamos? ¿Cómo es posible medir la contramayoría? Primeramente debo señalar que el modelo que introduzco obtiene fallas ante casos marginales y no ante casos claros. Esto es evidente si analizamos por ejemplo una decisión en la que la Corte sostenga que una ley aprobada por mayoría absoluta del Congreso que aumenta los salarios de los legisladores en un $400 \%$ no es inconstitucional. Evidentemente esta norma no es contramayoritaria en un sentido formal, pero sí en un sentido material, porque resulta claro que de saber con exactitud la opinión de todos los miembros del padrón electoral, una amplia mayoría de ellos rechazaría la norma en cuestión. No pretendo que el calificativo de contramayoritario material se relacione a la constitucionalidad de la norma o a su pertinencia o corrección, mi modelo simplemente no toma en cuenta estos dos factores. ${ }^{47}$ En otro sentido, supongamos que se expida

comunes y decisiones constitucionales. En palabras de Ackerman: “... a dualist Constitution seeks to distinguish between two different decisions that may be made in democracy. The first is a decision by the American People; the second by their government". Por supuesto que esta distinción se basa en cierta medida en los presupuestos de la representación. Distinguir — como Ackerman lo hace - entre la política cotidiana - Normal Politics — y la creación superior del derecho — Higher Lawmaking - , pp. 266-294, muestra un entendimiento profundo del sistema de mayorías y de la noción de representatividad. Para un estudio más cuidadoso de la teoría de Ackerman, véase Peña Freiré, Antonio, "Constitucionalismo garantista y democracia", Revista Crítica Jurídica, España, núm. 22, julio-diciembre de 2003, pp. 31-65, sobre el particular pp. 42-47. Nino se encuentra en desacuerdo con la distinción introducida por Ackerman, a la que acusa de ser una distinción vaga que adolece de no poder especificar los conceptos de pueblo utilizados en dicho análisis, véase Nino, Carlos Santiago, "La filosofía del control judicial de la constitucionalidad", Revista del Centro de Estudios Constitucionales, Argentina, núm. 4. 1989. Nino autodenomina su propia concepción de la democracia como epistemológica en contraposición a la noción dualista de Ackerman.

47 Esto es esencial porque para determinar cuándo una decisión es contramayoritaria, tampoco importa la corrección de la decisión, ni importa si la decisión anuló una acción positiva o negativa, simplemente importa que esta decisión atente contra otra decisión previa tomada por una mayoría (sin calificar a su vez esta decisión). Por ejemplo, si aceptamos que una parte sustancialmente mayoritaria del electorado desearía evitar el pago de tenencia, luego entonces la anulación por parte de la Corte de una ley expedida por 
una ley nacional — aprobada por una mayoría moderada - que permita el aborto en el país; el procurador general de la República o la Comisión Nacional de Derechos Humanos impugnan la norma en cuestión y la Corte declara inconstitucional la ley. Indudablemente aquí se ha tomado una decisión contramayoritaria, ¿pero de qué tipo? Los grupos liberales sostendrán que la decisión de la Corte ha sido contramayoritaria formal y materialmente pues sostendrán que dicha decisión va en contra de la mayoría legislativa y de las preferencias electorales, mientras que los conservadores probablemente argumentarán que esta decisión es contramayoritaria en un sentido material. Podemos adelantar que dado que una mayoría legislativa aprobó la norma, es meridiano que se ha producido una decisión contramayoritaria formalmente. ${ }^{48}$ La existencia o inexistencia de una contramayoría material debe ser producto del conocimiento de la opinión directa del electorado. En el presente caso supondré — dado que tengo elementos insuficientes de juicio- que lo más probable es que un electorado real hubiese desaprobado la norma y por tanto la decisión comentada efectivamente es una decisión contramayoritaria formal. ${ }^{49}$

el Congreso en tal sentido será una contramayoría material, sin importar si luego fuese posible por cualquier medio certero que se demuestre que económicamente y de forma objetiva era mejor la eliminación de tal impuesto para el crecimiento económico del país. Ningún factor objetivo de la norma anulada importa para la declarativa de contramayoría formal, material o concurrente, sólo importa la impopularidad o popularidad de la decisión frente a los grupos relevantes.

48 Me parece evidente que la contramayoría material es la más sencilla de demostrar y sólo es la contramayoría formal —o concurrente al tener el elemento formal tambiénla que nos presenta problemas. La determinación de la opinión legislativa es sencilla —al haber votado por la norma en cuestión externaron su opinión- y sólo se podrían producir umbrales sumamente pequeños y a mi juicio sin grandes efectos prácticos en relación con las abstenciones, pero dudo que puedan darse muchos casos en los que éstas produzcan resultados visibles.

49 El hecho de que a esta decisión le asigne tal calificativo obedece a la simple creencia de que existe una oposición al aborto en el país, sin importar si quien califica dicha decisión esté o no de acuerdo con ella. Como se aprecia, el modelo sólo presenta problemas en los casos poco claros pero esta no es razón para rechazarlo como una distinción importante. Inclusive, si comparamos su utilidad con otros modelos teóricos (aparentemente sin capacidad de ser probados empíricamente), por ejemplo el modelo de decisión por ponderación, tendremos entonces que el modelo ofrecido por nosotros puede ser más exacto. Los dos modelos hacen cosas distintas pero el modelo de ponderación aun cuando tiene casos difíciles es incapaz de resolverlos sin una gran argumentación. De hecho, inclusive después de mucho tiempo y estudio pocos podrán concordar en la primacía de dos 
Ahora bien, al haber introducido los conceptos anteriormente mencionados, ¿en qué cambia nuestra percepción del argumento contramayoritario? ¿Existe alguna diferencia teórica o práctica en la decisión contramayoritario o la legitimidad del control jurisdiccional? Creemos que sí.

El resultado de no considerar nuestra distinción nos lleva a ponderar de igual manera todo tipo de decisiones contramayoritarias y a no distinguir entre dichas decisiones para las consecuencias en materia de legitimidad y de representatividad. Creemos que una decisión contramayoritaria concurrente y perfecta es mucho más costosa en términos político-democráticos que las contramayorías formal o material imperfectas..$^{50}$ De estas últimas la contramayoría formal y la contramayoría material pueden tener costos mayores o menores según sea el grado de existencia de las respectivas contramayorías. Una contramayoría formal o material determinante pueden elevar cuantitativamente los costos políticos o democráticos respecto a una mayoría de la misma especie pero de un grado inferior. No es difícil imaginar el desarrollo de una teoría de la adjudicación democrática constitucional que argumente que las decisiones contramayoritarias concurrentes deben de ser mucho más sopesadas que las decisiones contramayoritarias en sentido formal y material. ${ }^{51}$

valores sumamente parecidos e igualmente importantes (por ejemplo al comparar vida, libertad, igualdad, respeto, etcétera) sin ser argumentativos y presuponer algo. Creo que es casi imposible demostrar científicamente la primacía de un valor sobre otro en el caso ofrecido, mientras que en el modelo de contramayorías bastaría con hacer una encuesta nacional, elector por elector y reduciendo al máximo todo factor de influencia y presión para obtener un resultado bastante exacto. Aun cuando la metodología sea complicada, en el método contramayoritario propuesto existe una solución aproximada que puede prescindir de argumentación, mientras que en el mucho más popular método de la ponderación no la hay. En este sentido, a pesar de las dificultades del método de ponderación no han cesado autores de sostener que x o y decisión de la Corte fue errada utilizando el método de ponderación, o como Dworkin, a proponerlo como método seguro en la adjudicación constitucional y en el hallazgo de la única respuesta correcta. Una consideración semejante podría ser hecha para la catalogación de contramayorías y el uso de esta distinción en la discusión de decisiones de la Corte.

50 Esperamos haber expresado la idea con claridad. Mediante la asunción de un mayor costo político por parte de la contramayoría concurrente no pretendemos sostener que las decisiones contramayoritarias en un sentido concurrente deben ser evitadas o que son nocivas a los efectos del sistema. Sin embargo, tienen un peso mucho mayor en la crítica y son mucho más complicadas de sostener.

51 Evitaré la profundización de este aspecto porque a mi juicio el desarrollo de tal teoría es ajeno a los fines de este trabajo. No dudo que en futuros trabajos sea posible 


\section{ARGUMENTACIÓN CONTRAMAYORITARIA}

La argumentación contramayoritaria se ha planteado en una gran cantidad de países de forma compleja y única. Algunas de estas discusiones se han desatado en Canadá, ${ }^{52}$ Francia, ${ }^{53}$ Nueva Zelanda, ${ }^{54}$ Austria, Alemania, Italia, Austria ${ }^{55}$ y por supuesto Estados Unidos.

Existen algunos argumentos planteados en contra de la legitimidad de la jurisdicción constitucional como la falta de legitimidad democrática de origen del juez constitucional, el rompimiento del orden democrático con decisiones contrarias a las mayorías o la concesión de un poder arbitrario a jueces no responsables ante el electorado. A contrario sensu, muchos más argumentos y teorías han sido esgrimidos en defensa del control jurisdiccional. Esto es sencillo de explicar dado que existe una cultura —en incremento gradual - que acepta al control jurisdiccional como un paradigma y requisito inherente al Estado constitucional y porque argumentar en contra de la justicia constitucional y concretamente del Judicial

el desarrollo de tal distinción y la clarificación de las situaciones en donde es posible ponderar las distintas contramayorías al formular reglas generales de su determinación y peso político. La misma distinción contramayoritaria propuesta puede ser útil al momento de determinar en qué posturas la argumentación contramayoritaria se presentará como sustantiva o como una argumentación de grado.

52 Martin, Robert Ivan, The Most Dangerous Branch, Canadá, McGill-Queen's University Press, 2003. La visión de Martin es compleja, describe a la Corte Suprema canadiense como una institución perversa que ejerce la justicia constitucional de una manera no basada en principios y completamente discrecional. Inclusive Martin sugiere (p. 23) abolir a la Suprema Corte como una manera de salvar la democracia.

53 Para este tema véase Fernández Segado, Francisco, "Fétichisme de la loi, séparation des pouvoirs et gouverment des juges. Tres ideas-fuerza para el rechazo del control jurisdiccional de la constitucionalidad de las leyes en Francia", Teoría y Realidad Constitucional, España, núm. 19, 2007, pp. 45-73; y Tushnet, Mark, "Policy Distortion and Democratic Debilitarion: Comparative Ilumination of the Countermajoritarian Difficulty”, Michigan Law Review, Estados Unidos, vol. 94, núm. 2, 1995, pp. 245-301.

54 Keith, K. J, “A Bill of Rights for New Zealand? Judicial Review Versus Democracy”, New Zealand Universities Law Review, New Zealand, vol. 11, núm. 4, 1985, pp. 307-322. Discusión a raíz de la problemática de la inclusión de un Bill of Rights y las facultades interpretativas que daría a la corte.

55 Cappelletti, Mauro, Obras de Mauro Cappelletti, México, Porrúa-UNAM, 2007, pp. 256-280. 
Review es presuponer una noción de democracia ${ }^{56}$ y muchos argumentos son hechos en términos que ignoran la noción de democracia misma y por tanto no deben ser catalogados como contramayoritarios.

En lo subsecuente analizaremos los argumentos que consideramos principales a la discusión contramayoritaria. Previo a ello, nos interesa introducir una distinción importante. A lo largo de la discusión contramayoritaria frecuentemente se han esgrimidos argumentos que aparentemente representan un punto de vista contramayoritario pero en realidad cuestionan sólo el grado, metodología o alcances de la Judicial Review, jurisdicción constitucional en general o simplemente la interpretación constitucional. ${ }^{57}$ Sin embargo, el cuestionar el grado - no la sustanciade la jurisdicción constitucional es presuponer una aceptación de la justicia constitucional y luego entonces enfocarse en cuestiones incidentales. ${ }^{58}$

En nuestra concepción, existen tres razones que en su conjunto legitiman a la justicia constitucional y le permiten sobrepasar la imputación antidemocrática de la objeción contramayoritaria:

56 No me atrevo a decir que la crítica contramayoritaria presupone de forma total a la democracia como una democracia directa y popular. Sin embargo, es fáctico argumentar que por lo menos el principio mayoritario debe jugar un papel toral en la crítica contramayoritaria al incorporar este principio como base de su conceptualización democrática. De tal suerte, el contramayoritarismo presupone en gran medida una noción democrático-constitucional regida por el principio mayoritario, regida por decisiones procedimentales y celosa de cotos jurisdiccionales no abiertos a las decisiones de la mayoría. Es obvio que la crítica contramayoritaria cambiaría radicalmente su carácter si se esgrime en Estados Unidos y posteriormente en la democracia de la antigua Atenas. De igual forma podríamos sostener que presupone lo que Dworkin nomina premisa mayoritaria en contraposición a su concepción constitucional de la democracia. Véase nota 52.

57 Esta distinción no carece de importancia y de cierta correlación indispensable. Baste señalar que el propio Marmor sostiene una de las dos grandes diferencias entre la interpretación legislativa y la interpretación constitucional; consiste en que la interpretación Constitucional se encuentra sujeta a la revisión judicial y por tanto las decisiones de la corte no pueden ser revertidas por la legislación ordinaria. Marmor, Andrei, Interpretación y teoría del derecho, trad. de Marcelo Mendoza, Barcelona, Gedisa, 2001, p. 220.

58 En el presente artículo evito discutir los alcances permitidos de la interpretación constitucional, pues la gradación en el argumento contramayoritario y en general la argumentación que en cierta forma presupone la validez de la justicia constitucional, en la forma en que previamente lo he descrito, exceden los propósitos de este artículo que es centrarse en la discusión sustantiva, pero que serán objeto de posteriores investigaciones. 
1. La jurisdicción constitucional tutela derechos procedimentales y sustantivos al asegurar la vigencia misma de la democracia.

2. La jurisdicción constitucional protege derechos minoritarios y finalmente.

3. La fuerza normativa constitucional es asegurada mediante la justicia constitucional. ${ }^{59}$

Sostenemos que a pesar de que existan diversos argumentos destinados a demostrar la legitimidad de la jurisdicción constitucional, éstos son, per se, insuficientes para legitimar la institución y por tanto una cofundamentación es necesaria.

En lo subsecuente basaremos nuestro análisis en estos tres argumentos ${ }^{60}$ en lo particular.

A) Se ha argumentado que la jurisdicción constitucional - y concretamente la Judicial Review - puede sobreponerse a la objeción contramayoritaria siempre y cuando su control se base en el aseguramiento de derechos procedimentales de naturaleza electoral que aseguran la vigencia de la democracia. La forma más refinada de este argumento se encuentra en John Ely, quien argumenta básicamente que el Judicial Review debe preminentemente eliminar obstrucciones del procedimiento democrático y en particular defender los derechos electorales al voto. ${ }^{61}$ La teoría de Ely

59 Con ello nos referimos a lo que algunos autores han denominado "operatividad constitucional" o "valor real constitucional"; en su más amplio sentido retórico, este argumento puede ser expresado mediante otro tipo de fórmulas - prevalecer constitucional, significado real de la palabra Constitución-.

60 Claro que existen más argumentos que los aquí planteados, entre ellos el argumento de la falta de alternativa institucional al control jurisdiccional por parte de jueces no electos, el argumento de la representación simbólica, el argumento fuertemente defendido por Nino de la estructura del razonamiento práctico judicial entre otras. Para una breve reseña de algunos argumentos no explorados en este artículo, consúltese Álvarez Álvarez, Fernando, "Legitimidad democrática y control judicial de constitucionalidad", Díkaion, Colombia, año 17, núm. 12, 2003, pp. 147-177.

61 Ely, John, Democracy and Distrust, Estados Unidos, Harvard University Press, 1980, p. 117. En palabras de Ely “...unblocking stoppages in the democratic process is what judicial review ought preeminently to be about, and denial of the vote seems the quintaessential stoppage". De igual forma para Ely la prioridad en esta defensa al proceso democrático deben ser los voting cases, que básicamente son aquellos cuya decisión es esencial para el proceso democrático y cuyas dimensiones decisorias no pueden ser delegadas a los representantes electos de forma segura. 
ha sido defendida en diversas formas al asumir la eficacia del fenómeno representativo y a la jurisdicción constitucional como un método simple del aseguramiento de estos derechos. Sin embargo, la argumentación procedimental de Ely presenta ciertos defectos. ${ }^{62}$ Principalmente puede argumentarse que Ely hace una distinción entre derechos sustantivos y derechos procedimentales; por ende, presupone la perfección de los mecanismos que aseguran la participación electoral, porque de lo contrario, Ely desconocería circunstancias que atentan contra derechos que aseguran derechos electorales. Sin embargo, la teoría de Ely intenta ser comprehensiva al sostener que los derechos sustantivos deben ser protegidos por el Judicial Review cuando la violación de éstos cause problemas en la representatividad. A primera vista este argumento parece aceptable, pero no lo es. Si los derechos sustantivos pueden ser tutelados cuando infieran en el fenómeno representativo electoral, ¿a qué grado debe ser la inferencia para poder tutelar el derecho correspondiente? Es evidente que el ejemplo paradigmático de Ely sería la anulación de una norma que prohibiese votar a personas de determinada raza, dado que directamente violaría un derecho electoral - el derecho prioritario al voto- y por tanto crearía problemas en el fenómeno representativo. Ely basa la tutela de derechos sustantivos principalmente en la tutela al derecho de la no discriminación — que acarrea problemas representativos. Un ejemplo de este segundo rubro podría ser el anular una ley de un Estado que prohibiese la traducción a lenguaje indígena de todo discurso, propuesta, propaganda o plan de campaña de los candidatos involucrados en una votación. Ely indudablemente argumentaría que esta decisión es correcta dado que al prohibir la traducción de propuestas y datos, se crearía un sesgo al electorado indígena y por tanto se le dificultaría la toma racional de decisiones, lo cual provocaría un stoppage en el proceso electoral. Estos dos casos son claros, pero ¿qué sucede cuando el análisis del Judicial Review como instrumento de defensa de derechos electorales y defensor del procedimiento democrático se contrasta con ejemplos poco claros? Supongamos que empleásemos la lógica de Ely en una norma que permitiese a las escuelas negar al acceso a la educación por bases raciales. La

62 Una fuerte acusación a Ely ha sido que su teoría del Judicial Review confunde conceptos de democracia. "...Ely seems to equate democracy with simple majoritarism". Véase Posner, Richard, Law, Pragmatism and Democracy, Estados Unidos, Harvard University Press, 2005, p. 233. 
postura que tendría que tomar un juez que siga la lógica procedimental de Ely no es del todo clara. Podría argumentarse que como la incidencia de tal norma no es directa - dado que no se le impide al individuo votar o informarse de las propuestas o acceder a sus derechos electorales- la norma no tendría por qué ser anulada. Claro que es sencillo argumentar en sentido contrario. Si una norma prohíbe la educación a determinado grupo se le niega un derecho que le permite discernir entre opciones y conocer diferentes ideologías. Un individuo menos educado tomará decisiones menos razonables que otro o simplemente tendrá una menor capacidad decisoria. Por tanto, aunque la influencia no es directa como en el primer ejemplo, o indirecta y clara como en el segundo, el Judicial Review debe tutelar tal derecho. La dependencia de la tutela de derechos sustantivos de derechos electorales y el procedimiento democrático es un punto débil en la teoría de Ely porque ésta es incapaz de establecer un criterio distintivo interno de la afectación directa. Así, nuevamente el juez debe valorar o ponderar el caso concreto y determinar si el derecho sustantivo afecta indirectamente o no al procedimiento democrático. Esta postura requiere una complicada gradación de derechos sustantivos que la teoría de Ely (Representation-Reinforcing) de la Judicial Review fue incapaz de formular. ${ }^{63}$ Nino parece concordar cuando afirma que este tipo de concepción del Judicial Review se dificulta cuando la participación equitativa en el proceso político presupone una democracia con requisitos mayores, lo que vuelve controvertida la defensa de ciertos derechos. ${ }^{64}$

63 La distinción entre derechos de participación-políticos y derechos sustantivos -a la no discriminación - es considerada por Ferreres como el rompimiento de las premisas procedimentales ante la dificultad de determinar la afectación indirecta al proceso de representación por parte de las normas sustantivas, o bien la tutela del derecho a la no discriminación; véase Ferreres Comella, Víctor, op. cit., nota 34, p. 59, y respecto a un análisis de la concepción procedimental de Ely véase pp. 53-68.

64 Nino, Carlos Santiago, Fundamentos de derecho constitucional, Buenos Aires, Astrea, 1992, p. 706. Nino considera que la corrección de las precondiciones democráticas hacen controvertida la defensa de ciertos derechos bajo la concepción de Ely. Entre más precondiciones deba un juez defender y su interpretación se vuelva menos mecánica, tanto mayor será la controvertibilidad de la tesis de Ely. La mecanicidad debe considerarse uno de los puntos esenciales de la teoría de Ely. Esta teoría sería satisfactoria si fuese mecánicamente posible determinar la afectación de la violación de derechos sustantivos al proceso democrático; como tal ejercicio es teórico y no empíricamente posible, el juez debe ponderar, con lo cual reasume su papel de actor controvertido y ante los ojos del electorado, discrecional. Bobbio realiza una contraposición entre reglas del 
Es por tanto la teoría de Ely — debido a la equivocidad descrita - insuficiente sin apoyo de una teoría complementaria para ofrecer un modelo de legitimidad de jurisdicción constitucional.

B) La protección de derechos minoritarios ha sido argumentada en diversas maneras como la legitimación de la jurisdicción constitucional. La Constitución debe ser un documento que proteja al pueblo de que lo acertadamente Alexis de Tocqueville denominó la tiranía de las mayorías. ${ }^{65} \mathrm{Si}$ irrestrictamente se permitiese a las mayorías tomar decisiones sin un control sustantivo, es obvio que las minorías se verían oprimidas y la Corte al decidir en el Judicial Review, se erige como protectora de estos derechos. La esencia del Estado constitucional moderno se define por la protección de ciertos derechos que deben ser puestos lejos del alcance del simple voto mayoritario. ${ }^{66} \mathrm{La}$ misma discusión en torno a la Corte se ha concentrado a partir de los años cuarenta en la interpretación de los derechos ${ }^{67}$ y concretamente los derechos minoritarios. Autores como Cappelletti, Dworkin ${ }^{68}$ y Raz han tomado por fundamento de la

juego democrático y reglas preliminares que permiten el desarrollo del juego, es decir, entre derechos presupuestos a la democracia y derechos propiamente democráticos que pueden servir a clarificar la distinción de Ely, véase Bobbio, Norberto, El futuro de la democracia, México, Fondo de Cultura Económica, 2008, pp. 26 y 27.

65 Para un estudio acerca de las modernas implicaciones de la tiranía de las mayorías, véase Sartori, Giovanni, Teoría de la democracia, trad. de Santiago Sánchez, Madrid, Alianza Universidad, 2001, pp. 170-182.

66 Esta argumentación no es nueva y ya había sido defendida por diversos autores. Una referencia contemporánea de esta argumentación se encuentra en Vidal Gil, Ernesto, "Justificación de la democracia y límites a la decisión por mayorías", Doxa, España, vol. 1, núm 15-16, 1994, pp. 254-238. Luego entonces, bajo este matiz garantista, la jurisdicción constitucional es legítima si protege lo que Garzón Valdés denomina el coto vedado de los derechos humanos.

67 Cepeda Espinosa, Manuel, "Los derechos y la interpretación de la nueva Constitución”, Externado Revista Jurídica, vol. 5, núm. 2, 1991, p. 9.

68 La postura de Dworkin a mi juicio debe considerarse incierta. Aun cuando indubitablemente se encuentra a favor del Judicial Review, Dworkin se encuentra mucho más interesado en el abordaje de cuestiones incidentales al argumento contramayoritario y en ocasiones da en cierta forma por supuesta su discutida legitimidad. Dworkin ha argumentado que es una violación al principio de equidad permitir que las mayorías sean jueces en su propia causa - los derechos mayoritarios $v s$. los derechos minoritarios - pero no es incisivo al no pronunciarse directamente por la legitimidad de la jurisdicción constitucional con base en la protección de los derechos humanos, véase Dworkin, Ronald, Los derechos en serio, trad. de Martha Gustavino, Barcelona, Ariel Derecho, 2002, pp. 
legitimidad de la justicia constitucional los derechos humanos en mayor o menor medida, derechos que tienen por objeto la defensa de intereses minoritarios. ${ }^{69}$ Recordemos que la democracia no es sólo regla de la mayoría, ${ }^{70}$ sino que implica también una protección a los derechos humanos; la Judicial Review debe centrarse en la eficacia de una democracia sustantiva $^{71}$ en oposición a procedimental, en cuyo supuesto el juez no tiene carácter antidemocrático. Nino se encuentra en desacuerdo con la legitimidad de la jurisdicción constitucional basada en la defensa de derechos humanos, ${ }^{72}$ en torno a ello argumenta que la revisión judicial de

222 y 223 . Sin embargo, su argumento basado en la equidad tiene evidentes tendencias a volverse una defensa de derechos minoritarios.

69 Mena Vázquez, Jorge, "Derechos humanos vs. democracia, sobre la legitimidad y naturaleza del control jurisdiccional de la legislación", Derechos Humanos México, México, año 1, núm. 2, 2000, p. 164. Los derechos humanos representan controles minoritarios en tanto alejan ciertas cuestiones fundamentales de la arena política y mayoritaria. Mena también considera a Nino dentro de estos autores, pero como se ha expuesto anteriormente Nino encuentra un desacuerdo en tomar como legítima la jurisdicción constitucional ejercida exclusivamente para la protección de derechos humanos.

70 Dworkin lo ha sostenido de forma clara: "La teoría constitucional sobra la cual se basa el gobierno de los Estados Unidos no es una simple teoría mayoritaria". Dworkin, Ronald, op. cit., nota 50, p. 211. De igual forma Dworkin ha argumentado que si bien la democracia no implica que los jueces deban de tener la última palabra en ciertas decisiones (es decir, no considera a la Judicial Review como un requisito sine qua non democrático) tampoco implica que éstos no puedan tenerla y por tanto la institución puede ser compatible con la democracia misma. Al respecto véase, Dworkin, Ronald, "The Moral Reading and the Majoritarian Premise", en Hongju, Harold y Slye, Ronald, Deliberative Democracy and Human Rights, Estados Unidos, Yale University Press, New Haven and London, 1994, pp. 81-115, sobre el particular p. 86. Dworkin efectivamente comprende que una concepción de democracia debe ser presupuesta al argumento contramayoritario - en su caso argumentando acerca de la lectura moral de la Constitución - para evaluar la compatibilidad de las instituciones. Sin embargo, parece mucho más interesado en el grado al que la interpretación constitucional puede ser llevado y no tanto en la legitimidad de la jurisdicción constitucional de forma sustantiva: "[w]e do not have a positive argument in favor of judicial review..." (111).

71 Barak, Aharon, Un juez reflexiona sobre su labor: El papel de un tribunal constitucional en una democracia, México, SCJN, 2008, p. 32.

72 Gargarella concuerda con Nino. Véase Gargarella, Roberto, "La dificultad de defender el control judicial de las leyes”, Isonomía, México, núm. 6, 1997, pp. 64-67. Gargarella considera que la sola defensa de derechos humanos es un argumento pobre para la defensa de la justicia constitucional. 
decisiones mayoritarias no es requisito sine qua non para la protección de tales derechos. ${ }^{73}$

Cabe señalar que la defensa de los derechos humanos ha sido cuestionada en su modo operativo. Existe un antiguo y magnífico estudio ${ }^{74}$ de Robert Dahl en el que se conceptúa a la Corte, no como una defensora de los derechos humanos, sino más bien como una institución alineada con el poder dominante. En el concepto de Dahl, las opiniones de la Corte raramente difieren de las opiniones políticas de la mayoría dominante legislativa en los Estados Unidos. ${ }^{75}$ Claro que la argumentación de Dahl es fáctica ${ }^{76}$ y no teórico-constitucional, por lo que aun cuando la aseveración de que una Corte rara vez ejerciese la jurisdicción constitucional

73 Nino, Carlos Santiago, op. cit., nota 43, p. 680. La argumentación de Nino al respecto es confusa y en mi opinión incorrecta. Nino argumenta que "Es perfectamente concebible, por objetable que pudiera ser por otras razones, un sistema jurídico que reconociera derechos individuales, aunque su protección sólo quedara en manos de las mayorías a través de un proceso democrático y no hubiera revisión judicial de sus decisiones". A este argumento es posible objetarse que si Nino acepta la tesis anteriormente expuesta, también debe aceptar que es posible concebir un sistema jurídico en donde los derechos humanos quedasen al arbitrio - por objetable que pudiera ser- de un monarca, un colegio de sacerdotes, una academia de profesores de derecho, o ¿por qué no? del mismísimo Führer y que no hubiera revisión judicial de sus decisiones. La argumentación de Nino es forzada y llevada a sus últimas consecuencias, inaceptable. Una función legítima del Judicial Review es la protección de derechos minoritarios. En su lugar, Nino prefiere aceptar a la estructura del razonamiento práctico judicial basado en la lógica justificadora de las decisiones.

74 Dahl, Robert, "La toma de decisiones en una democracia: la Suprema Corte como creadora de políticas nacionales", en Nava Gomar, Salvador (comp.), Tribunales constitucionales y democracia, México, Suprema Corte de Justicia, 2007, pp. 141-161. Ofrezco también la referencia original véase Dahl, Robert, "Decision-Making in a Democracy: The Supreme Court as a National Policy Maker", Journal of Public Law, Estados Unidos, vol. 6, 1957, pp. 279-295.

75 Ibidem, p. 149. Dahl argumenta que si Roosevelt tuvo problemas con la Corte, no fue porque la Corte defendiese derechos humanos o individuales. Al contrario, la Corte se encontraba políticamente escindida y Roosevelt tuvo que esperar cuatro años para hacer la primera designación de un Justice, una situación poco común.

76 Para un studio más reciente de la temática estudiada por Dahl, véase MgGuire, Kevin y Stimson, James, "The Least Dangerous Branch Revisited: New Evidence on Supreme Court Responsiveness to Public Preferences", The Journal of Politics, vol. 66, núm. 4, 2004, pp. 1018-1035. En particular véase pp. 1027-1032, donde se estudia la influencia de la opinión pública directa en los resultados de las decisiones de la Suprema Corte. 
en defensa de derechos minoritarios, ello no implicaría que el control jurisdiccional fuese ilegítimo cuando efectivamente se ejerciera del modo descrito. Por ello existen autores que propugnan la formulación de una teoría democrática del Judicial Review basada en la protección efectiva de los derechos humanos. Independientemente del magnífico análisis de Dahl, es posible que la jurisdicción constitucional sea legítima cuando efectivamente protege derechos humanos. ${ }^{77}$ Sin embargo, quizás sea incorrecto basar la legitimidad del Judicial Review exclusivamente en la tutela de los derechos humanos. De igual forma, existen autores que al congeniar los dos argumentos descritos anteriormente (defensa de derechos procedimentales democráticos y derechos sustantivos) argumentan una defensa ecléctica del control jurisdiccional. ${ }^{78}$ El considerar la jurisdicción constitucional legítima cuando protege derechos minoritarios parece incorrecto porque entonces implicaría que nada más los derechos minoritarios pueden ser protegidos mediante el Judicial Review y no la operatividad intrínseca de la Constitución -o aparejaría considerar un derecho minoritario el respeto a la norma constitucional-, lo cual de cierta forma crearía rangos de normas constitucionales (dignas de protección y no dignas de protección). De igual manera, implicaría que los derechos minoritarios cayesen en la equivocidad en que la distinción de Ely incurre. Por tanto, si nuestra argumentación es correcta, consideramos

77 Perry, Michael, The Constitution, the Courts and Human Rights, Estados Unidos, Yale University Press, 1982. Concretamente Perry propone una tercera vía entre el denominado interpretive y non-interpretive Judicial Review basada en la protección de los derechos humanos. De cualquier forma, es curioso el hecho del punto de vista de Perry que basa su concepto de la función del Judicial Review al presuponer una democracia procedimental y no sustantiva (noción que ampliamente acepta la defensa de los derechos como fundamento democrático): "The notion of democracy on which I rely is primarily procedural, not susbtantive... I regard democracy as a system for making govermental decisions. Democracy is to be defined in terms of procedures not in terms of substantive policy..." (p. 3). Empero Perry afirma que el non-interpretive review debe centrarse en la defensa de las personas marginadas (pp. 146-162).

78 Barroso, Luis Roberto, El neoconstitucionalismo y la constitucionalización del derecho, México, UNAM, Instituto de Investigaciones Jurídicas, 2008, pp. 60 y 61. Barroso argumenta que la jurisdicción constitucional debe proteger, 1 . Derechos procedimentales para la expresión democrática, y 2. derechos fundamentales coetáneos a la democracia sustancial. Ely indudablemente estaría de acuerdo en el primero, aunque en desacuerdo parcial con el segundo. 
cuando menos cuestionable, basar la legitimidad de la jurisdicción constitucional exclusivamente en la protección de derechos minoritarios.

C) Finalmente es posible argumentar la legitimidad de la jurisdicción constitucional mediante la tutela de la fuerza normativa de la Constitución. La fuerza normativa de la Constitución ${ }^{79}$ es el aseguramiento y vigencia de los preceptos constitucionales que permite que la Constitución sea el centro de la vida del Estado, sean éstos o no derechos procedimentales o democráticos. Una Constitución aleja ciertas cuestiones de la decisión mayoritaria; la jurisdicción constitucional es el aseguramiento de estos cotos.

Ahora bien, existe dentro de toda Constitución o práctica constitucional una noción de democracia y es posible que al variar la noción democrática que se tenga, la objeción contramayoritaria será mayor, menor o diferente. Por ejemplo, el presupuesto ${ }^{80}$ de una noción sustancial de democracia generaría que las decisiones contramayoritarias no lo fuesen si éstas defendiesen derechos humanos. Debe establecerse una distinción entre democracia formal y sustancial. ${ }^{81} \mathrm{La}$ objeción contramayoritaria es una variable dependiente de la noción de democracia. La noción de democracia imperante en la actualidad dista de ser una democracia meramente procedimental, como la defendida por Schumpeter.

79 Con ello no nos referimos a la democracia misma. A pesar de que la consolidación democrática puede ser una consecuencia de la jurisdicción constitucional, concordamos con Nohlen de que ésta no debe de ser su función primaria. Véase Nohlen, Dieter, Derecho y política en su contexto, México, UNAM, Instituto de Investigaciones Jurídicas, 2008, pp. 13 y 14.

80 Autores como Winter sostienen que la formulación bickeliana está sostenida por presupuestos. Bajo la óptica de Winter son dos, a saber, la presuposición de que el proceso electoral es definitivo en la democracia y segunda, que el juez constitucional - unelected judiciary en Winter - no es políticamente responsable. Véase Winter, Steven, “An Upside/Down View of the Countermajoritarian Difficulty", Texas Law Review, Estados Unidos, vol. 69, núm. 7, p. 1920. La tesis de Winter es útil si tomamos en cuenta que la objeción contramayoritaria se debilitaría de forma considerable en cualquier sistema democrático en el cual el proceso electoral no fuese presupuesto como el resultado definitivo mismo, sino como parte —inclusive esencial— del propio modelo.

81 Al respecto véase Lilia Uloa, Ana, "Democracia sustancial y el coto vedado de los derechos humanos”, Isonomía, México, núm. 10, 1999, pp. 191-218. 
Claro que la democracia está basada en un principio mayoritario, pero éste no es absoluto ni puede sobrepasar ciertos derechos minoritarios. ${ }^{82}$ La democracia es más que mayorías y representa no sólo el cómo debe ser decidido, sino, hasta cierto punto, límites a lo que puede ser decidido.

Cierto es que, como habíamos argumentado, el problema de la legitimidad democrática derivada del juez constitucional, crea problemas severos al concepto mismo de un tribunal constitucional como institución democrática, pero aun cuando sus jueces no son electos de una forma directamente democrática, al menos lo son por cuerpos o funcionarios efectivamente elegidos de tal manera. ${ }^{83}$ Algunos ejemplos son ${ }^{84}$ Chile (en donde la propia Suprema Corte participa en la designación), Ecuador (en donde es constitucionalmente obligatorio considerar la paridad y representatividad de los sexos en la conformación del Tribunal, y el curioso caso de Guatemala (en donde la Universidad de San Carlos participa me-

82 La distinción de Dworkin entre democracia bajo una premisa mayoritaria y concepción constitucional de la democracia es interesante pero no ha tenido la misma relevancia en la literatura politológica como en la jurídica. Dworkin distingue entre la Constitución vista como una premisa mayoritaria con una relación estadística con los votantes con la contrastante concepción constitucional de la democracia, que genera con base en la lectura moral constitucional una visión de relación colectiva con los electores y supuestos miembros de una mayoría. Sin embargo, la distinción de Dworkin está hecha ex post a su teoría inicial de la lectura moral de la Constitución —una teoría interpretativa y no tanto legitimadora- y por tanto cabe cuestionarse la validez de sus inferencias. Véase Dworkin, Ronald, "The Moral Reading and the Majoritarian Premise", op. cit., nota 52, pp. 96, con relación a su concepto de democracia constitucional, y 89-90 referente a su principio integrador interpretativo - inclusión del novelista en cadena a la adjudicación constitucional-.

83 Van Hocke, Mark, "Judicial Review and Deliberative Democracy: A Circular Model of Law Creation and Legitimation", Ratio Juris, Inglaterra, vol. 14, núm. 14, p. 416. Claro que es probable que los defensores del argumento contramayoritario argumentasen que no podemos presuponer que tales órganos actúen en forma representativa de las preferencias electorales y que por tanto su elección en cierta forma se encuentra viciada. Sin embargo, si un partidario del argumento contramayoritario puede presuponer que los cuerpos colegiados realmente actúan como lo harían las preferencias electorales, deben presuponer también que la elección de estos cuerpos acerca de jueces constitucionales es representativa. Esta suposición es por supuesto falsa, y evidencia los problemas de suponer una representación efectiva en cuerpos legislativos.

84 Base de Datos Políticos de las Américas (2008). Normas de la justicia. Análisis comparativo de Constituciones de los regímenes presidenciales. Internet. Georgetown University y Organización de Estados Americanos. http://pdba.georgetown.edu/Comp/ Judicial/Constitucional/designacion.html 
diante una designación y por lo tanto se incluye obligatoriamente a la academia en la Corte Constitucional). Consideramos que la representatividad no debe de ser un criterio para la composición de un tribunal constitucional. La jurisdicción constitucional provee decisiones sobre temas voluntariamente alejados de la discusión mayoritaria y fomentar la representatividad del tribunal sería acercarlo a las decisiones mayoritarias y políticas de las cuales se le había tratado de apartar inicialmente.

Ahora bien, la propia redacción constitucional trae a la arena las provisiones constitucionales mismas como materia interpretativa. La mayoría de las Constituciones lentamente se han apartado de sus redactores y han adquirido vida propia — como el concepto alemán de la lebende verfassung o el concepto de living three retomado por Waluchow-. Bajo este punto de vista, la operatividad de la Constitución como fuerza legitimadora del Judicial Review es cuestionada cuando la abstracción y generalidad de los términos provocan que la Constitución no pueda ser aplicada - enforced - sin recurrir a interpretaciones equívocas en las cuales prevalecerá la voluntad del Poder Judicial — no electo ni representativosobre aquella de la legislatura. Marmor sostiene que al permitir este tipo de interpretación, los jueces toman decisiones morales y no jurídicas y, por tanto, no deberían tener ese poder, ${ }^{85}$ esta postura parece compartida por el propio Waldron, quien piensa que la creación de previsiones constitucionales (charters, ${ }^{86}$ bill of rights) dificulta la flexibilidad del discurso

85 Marmor, Andrei, “Are Constitutions Legitimate?”, Problema. Anuario de Filosofía y Teoría del Derecho, México, núm 1, 2007, pp. 73-115, en lo particular 113. Si bien Marmor concede que un argumento equitativo o basado en el principio de equidad - como el abordado por Dworkin - puede cuestionar firmemente la idea de que una mayoría deba de prevalecer, se manifiesta en contra de permitir esta interpretación moral - o bien un Judicial Review basado en una lectura moral de la Constitución- dado que la abstracción de la terminología constitucional evita el aterrizaje en concreto de los preceptos constitucionales y por tanto la formación de un consenso común o de lo que Dworkin y Waluchow denominan precomitmentt, concepto que estos autores requieren para fundamentar su propia teoría de una lectura moral.

86 Una contribución relativamente reciente a esta discusión ha sido aportada por Waluchow, quien retoma una metáfora empleada por Edwards para conceptualizar a una Constitución como un árbol viviente, lo que permite que los valores morales sean desarrollados para adaptarse al cambio contextual. Véase Waluchow, W. J., "A Common Law Theory of Judicial Review", Problema. Anuario de Filosofia y Teoría del Derecho, México, núm 1, 2007, pp. 117-139, y en particular 126. El propio Waluchow conceptualiza su teoría como aplicable a un contexto de common law, pero sus aplicaciones pueden 
político. La lectura moral de la Constitución, y la facultad del juez constitucional de interpretar a ésta basado en la coherencia interpretativa y una moral basada en el precompromiso constitucional, son conceptos que en cierta forma Dworkin ha supeditado a los beneficios de la justicia constitucional. ${ }^{87}$ Jeremy Waldron ha criticado en particular este aspecto de la fundamentación de Dworkin, ya que sostiene que aceptar el argumento de Dworkin equivale a conceder que las condiciones de legitimidad de la jurisdicción constitucional se encuentran supeditadas individualmente a los resultados que puede producir. ${ }^{88}$ Waldron concede a Dworkin: 1) la existencia de una conexión entre derechos y democracia, 2) la relación de ciertos derechos individuales con las condiciones de legitimidad de las decisiones mayoritarias, y admite que 3) es una petición de principio discutir las condiciones de la democracia apelando a nociones democráticas diferentes, ${ }^{89}$ pero afirma que la democracia sufre cuando las condiciones democráticas de la misma son impuestas por una institución no democrática. ${ }^{90} \mathrm{Si}$ bien es cierto que esta discusión se ha centrado en gran medida en las facultades interpretativas de un tribunal constitucional o corte con capacidad de ejercitar el Judicial Review, también lo es que centran la

ser formidables en ordenamientos jurídicos de civil law con Constituciones escritas que incluyan catálogos de derecho.

87 ¿La Constitución es más justa si sus restricciones sobre el gobierno de la mayoría son mínimas?, Dworkin, Ronald, El imperio de la justicia, Barcelona, Gedisa, 1992, p. 167. Dworkin parece sostener que los beneficios de la jurisdicción constitucional se traducen a una sociedad más justa que sin ella, a pesar de su carácter aparentemente contramayoritario.

88 Una constante a lo largo de su obra, Waldron, Jeremy, Law and Disagreement, USA, Oxford University Press, 1999, p. 302. De igual forma Waldron se basa en la distinción entre democratic ends y democratic means (fines y medios democráticos) para contrastar el carácter antidemocrático de la medida de justificación sugerida por Dworkin. Esta distinción es útil para identificar en qué aspectos particulares caerá la imputación antidemocrática.

89 Ibidem, p. 302.

90 La afirmación de Waldron es confusa, si bien admite que las condiciones democráticas sólo pueden ser fijadas conociendo un concepto de democracia, el sostener que la democracia se devalúa en cierta forma cuando sus condiciones son impuestas por instituciones no democráticas, ¿no presupone una noción de democracia que no ha explicitado? ¿O adapta para el argumento concreto la concepción constitucional de la democracia dworkiniana? 
discusión en la forma de interpretar ${ }^{91}$ derechos y lenguaje constitucional y no tanto — como Bickel inicialmente lo hiciera - en la calidad de los operadores.

\section{CONCLUSIONES}

Creemos que el argumento contramayoritario posee una fuerza singular y especial que se incrusta en lo más profundo de la tradición democrática contemporánea. Es sencillo explicar el porqué la objeción contramayoritaria ha recibido la atención académica y ha causado polémica y controversia. Sin embargo, existe una natural tendencia del argumento contramayoritario que debe ser analizada con detenimiento. Esta objeción se ha suavizado con el paso del tiempo y comienza paulatinamente a formularse en términos críticos en contra de la jurisdicción constitucional ejercida de forma incontrolada y no basada en principios. La objeción de Bickel ha evolucionado de ser un argumento sustantivo a un argumento de grado. Claro que no tengo una respuesta definitiva y completamente correcta al sollen de esta gradación argumentativa..$^{92}$ No puedo afirmar que exista un criterio uniforme que un tribunal constitucional

${ }^{91}$ En cierta forma las objeciones de Marmor son argumentación de grado, pero puede convertirse en argumentación sustantiva en contra del Judicial Review si logra probar su premisa de que la judicatura debe abstenerse de tomar decisiones morales, o hacer una lectura moral de la Constitución en palabras de Dworkin. Aun cuando Marmor se centre en los términos amplios de la constitución estadounidense tiene implicaciones evidentes en el argumento contramayoritario en sí. Si una norma constitucional sostiene algo evidente y claro, que no genere controversia, la invalidación de una norma promulgada por el Congreso, por parte de la Corte no generará controversia alguna. Es en esa posibilidad interpretativa en donde reside el nuevo conflicto de la legitimidad de la jurisdicción constitucional.

92 Este viraje en la argumentación contramayoritaria es sumamente interesante y merece un profundo estudio que excede los propósitos de este trabajo. En efecto, si la argumentación contramayoritaria cesa de cuestionar la legitimidad de la jurisdicción constitucional para formular una objeción a la extensión en que ésta puede ser ejercida, entonces evidentemente se ha modificado de ser una argumentación sustantiva a una argumentación de grado. De este modo, argumentar la ilegitimidad de una interpretación constitucional o la invalidación de una norma por parte de un tribunal constitucional o una corte, no necesariamente implica contramayoría, porque dentro de dicha argumentación se presupone la legitimidad inicial del ejercicio de la jurisdicción constitucional, aun cuando se cuestione con posterioridad los alcances legítimos de la misma. 
deba seguir al ejercer la jurisdicción constitucional ni tampoco ofrezco respuesta alguna al grado al que puede ser llevada la interpretación constitucional. Estas preguntas, que inicialmente fueron secundarias a la objeción contramayoritaria se han convertido verdaderamente en las grandes preguntas del derecho constitucional de nuestro tiempo. A ellas no ofrezco respuesta alguna porque reconozco que no tengo ninguna respuesta que pueda ofrecer que no sea debatible, controversial y probablemente incorrecta. Sostener una respuesta firme frente a estas inquietantes preguntas es a la vez sostener y presuponer una noción de democracia, filosofía, política, derecho. ${ }^{93}$

Dentro del curso de este artículo, se ha tratado - en la medida de lo posible - de mostrar los argumentos en pro y en contra de la justicia constitucional en lo concerniente al argumento contramayoritario. Se pretendió mostrar una lectura crítica de los argumentos que se han esgrimido en esta acalorada discusión y se intentó de igual manera probar que la argumentación contramayoritaria es per se insuficiente para deslegitimar la jurisdicción constitucional. Sin embargo, la refutación o relativa refutación de la postura contramayoritaria no es sencilla y por tanto es nuestra postura que una argumentación singular en favor de la legitimidad de la jurisdicción constitucional es insuficiente y requiere su complementación con argumentaciones distintas para contener la objeción hecha inicialmente al Judicial Review. Es por tanto en esta conjunción

93 Durante este breve artículo intenté ser claro respecto a mi postura. Veo con ojos críticos el argumento contramayoritario pero reconozco en él una seria objeción a la justicia constitucional. Empero, considero que de la lectura crítica de la argumentación expuesta en los anteriores apartados podemos concluir que no existe una singular fundamentación de la legitimidad de la acción de los tribunales constitucionales, o bien de la jurisdicción constitucional en general. Mi postura se centra eminentemente en una co-fundamentación del modelo de legitimidad de la jurisdicción constitucional. Los argumentos establecidos al final del presente artículo creo exponen mi postura integradora de la argumentación necesaria para fundamentar la legitimidad de la jurisdicción constitucional. Por supuesto que no ofrezco respuesta alguna; omito por completo determinar el grado de interpretación válida de la interpretación constitucional o el grado en que la interpretación puede ser determinada por un tribunal constitucional. Omito estas dos preguntas porque en mi artículo me ocupo de forma exclusiva del argumento contramayoritario en sentido puro —omito también hacer una escala de gradaciones-; por tanto, ambas preguntas, por más loable y necesaria que su respuesta puede ser, exceden el objeto de estudio de este artículo. 
argumentativa en donde reside la legitimidad de la jurisdicción constitucional y no de forma unívoca en una única razón legitimadora.

Concluyo al afirmar que la justicia constitucional es legítima - aun cuando deba ejercerse cuidadosamente-, pero su condición de legitimidad no reside en una única razón, sino en una complejidad funcional social que es única y necesaria. La justicia constitucional es legítima cuando menos porque 1) protege (o debe proteger) derechos de las minorías $^{94}$ al interpretar y aplicar preceptos constitucionales que inclusive las mayorías han dejado fuera de la arena política; 2) tutela derechos procedimentales y sustantivos que conforman la esencia del régimen democrático, y finalmente porque 3) la justicia constitucional da su significado verdadero a la palabra Constitución.

94 Recordemos que normalmente las Constituciones suponen y requieren controles contramayoritarios. La democracia representativa es en cierto sentido contramayoritaria. 